\title{
Field efficacy of novaluron for control of Colorado potato beetle (Coleoptera: Chrysomelidae) on potato
}

\author{
G.C. Cutler ${ }^{\mathrm{a}, *}$, C.D. Scott-Dupree ${ }^{\mathrm{a}}$, J.H. Tolman ${ }^{\mathrm{b}}$, C.R. Harris ${ }^{\mathrm{a}}$ \\ ${ }^{a}$ Department of Environmental Biology, Ontario Agricultural College, University of Guelph, Guelph, Ont., Canada N1G 2 W1 \\ ${ }^{\mathrm{b}}$ Southern Crop Protection and Food Research Centre, Agriculture and Agri-Food Canada, 1391 Sandford St., London, Ont., Canada N5V 4T3
}

Received 24 March 2006; received in revised form 5 July 2006; accepted 6 July 2006

\begin{abstract}
Field trials were conducted in 2003 and 2004 to assess the effectiveness of novaluron (Rimon 10EC), a benzoylphenyl urea chitin synthesis inhibitor, for Colorado potato beetle, Leptinotarsa decemlineata (Say), management on potato. Foliar applications of novaluron did not significantly reduce numbers of $L$. decemlineata adults, egg masses, or first instar larvae, but second-fourth instars were greatly suppressed. Although an application rate of $12.5 \mathrm{~g} \mathrm{AI} \mathrm{ha}^{-1}$ provided unsatisfactory protection, rates of 25 and $50 \mathrm{~g} \mathrm{AI} \mathrm{ha}{ }^{-1}$ proved effective when applied 2 days after second instars were first observed on plants. These rates were much less effective when applied 2 days after observance of egg masses. At $50 \mathrm{~g} \mathrm{AI} \mathrm{ha}^{-1}$, novaluron provided excellent, prolonged protection, whether applied twice a season, or once in alternation with imidacloprid. Defoliation was minimized, resulting in yields 3.8-5.2 times greater than those harvested from control plots. The results suggest that novaluron could be a valuable tool in future L. decemlineata management programs.

(C) 2006 Elsevier Ltd. All rights reserved.
\end{abstract}

Keywords: Colorado potato beetle; Leptinotarsa decemlineata; Novaluron; Imidacloprid; Potato

\section{Introduction}

Profitable potato production continues to be threatened by Colorado potato beetle, Leptinotarsa decemlineata (Say), the most destructive insect defoliator of potato in the world. Having developed resistance to virtually all insecticides used against it (Hare, 1990; Bishop and Grafius, 1996; Mota-Sanchez et al., 2006), the beetle is considered one of the most severe agricultural pests in terms of insecticide resistance. Unfortunately, limited commercial utility of biological, cultural and biotechnological control options means that growers remain heavily reliant on insecticides. While imidacloprid remains the insecticide of choice for $L$. decemlineata control throughout most of North America, imidacloprid resistance, or its onset, has been reported (Mota-Sanchez et al., 2000, 2006; Olson et al., 2000; Tolman et al., 2005a). Acetamiprid was

\footnotetext{
*Corresponding author. Tel.: + 15198244120 X53066/52477; fax: +15198370442 .

E-mail address: cutler@uoguelph.ca (G.C. Cutler).
}

recently registered in Canada and the United States for $L$. decemlineata control, as was thiamethoxam in the United States, and both countries are considering registration of other neonicotinoid (chloronicotinyl) insecticides. However, since cross-resistance has been reported among compounds within this class (Mota-Sanchez et al., 2006), rotation of neonicotinoids will be an ineffective long-term resistance management strategy.

Increased use of selective, reduced risk insecticides could result in better $L$. decemlineata management by increasing the role of natural enemies in potato agroecosystems, thereby reducing reliance on insecticides. Potato insect pest management programs adopting reduced risk products have achieved high yields and low pest densities equivalent to those in conventional fields treated with broad-spectrum insecticides, with the added advantage of conserving high predator densities (Hilbeck et al., 1998; Reed et al., 2001; Koss et al., 2005). Further, the mode of action of selective compounds is usually different than that of conventional insecticides, making them effective alternatives in resistance management programs. 
Novaluron is a non-systemic benzoylphenyl urea insect growth regulator with potent insecticidal activity against several important foliage feeding insect pests, and very low toxicity to mammals, birds, and earthworms (Ishaaya and Horowitz, 1998). By inhibiting chitin formation, novaluron selectively targets immature insect stages, causing abnormal endocuticular deposition and abortive molting. While incompatibility with natural enemies has been reported (Cutler et al., 2006), the compound generally is selective in favor of non-target organisms (Ishaaya et al., 2001, 2002; Cabrera et al., 2005), giving it good potential in integrated pest management (IPM). Novaluron has demonstrated good insecticidal activity against $L$. decemlineata in laboratory and field experiments (Malinowski and Pawinska, 1992; Linduska et al., 2001, 2002; Sewell and Alyokhin, 2003; Cutler et al., 2005a). Field studies were conducted in 2003 and 2004 to further evaluate the efficacy of novaluron against $L$. decemlineata on potato. Specifically, the experiment in 2003 sought to determine the optimal timing and rate of application of novaluron for $L$. decemlineata control, and to compare results with control by foliar applications of imidacloprid. The 2004 experiment compared levels of control by altered foliar applications of novaluron and imidacloprid.

\section{Materials and methods}

\subsection{Chemicals}

Novaluron (Rimon ${ }^{\circledR} 10 \mathrm{EC}, 100 \mathrm{~g} \mathrm{AI} \mathrm{L}^{-1}$ ) was supplied by Makhteshim-Agan of North America Inc. (Raleigh, NC). Imidacloprid (Admire ${ }^{\circledR} 240 \mathrm{~F}, 240 \mathrm{~g} \mathrm{AI} \mathrm{L}^{-1}$ ) and azinphosmethyl (Guthion ${ }^{\circledR} \mathrm{SC}, 240 \mathrm{~g} \mathrm{AI} \mathrm{L}^{-1}$ ) were supplied by Bayer CropScience Canada Inc. (Calgary, Alta., Canada). Dimethoate (Lagon ${ }^{\circledR} 480 \mathrm{E}, 480 \mathrm{~g} \mathrm{AIL}^{-1}$ ) was supplied by United Agri Products (Dorchester, Ont., Canada).

\subsection{Optimal timing and rate of application-2003}

Potato seed pieces (cv. Kennebec) were planted at the University of Guelph-Simcoe Research Farm (Simcoe, Ont., Canada) on May 22 in four-row, $13 \times 4 \mathrm{~m}$ plots, each separated by $3 \mathrm{~m}$ spray lanes. Eight treatments were replicated four times in a randomized complete block design. By 15 June, post-diapause $L$. decemlineata adults colonized experimental plots and began feeding and ovipositing on plants. Since only ca. $60 \%$ of potato plants had emerged in the experimental plots by this time, these adults and egg masses were removed to prevent premature defoliation. Removed egg masses were destroyed and adults were held at $8{ }^{\circ} \mathrm{C}$ and a photoperiod of 0:24 (L:D). Adults and egg masses were removed from the experimental plots every $2-3$ days until 22 June, by which time approximately $100 \%$ of potato plants had emerged. On 23 June, $L$. decemlineata adults either previously removed from the experimental plots or collected from a nearby field were distributed on the middle two rows of each plot, at a rate of 20 adults per plot.

Foliar treatments were applied using a tractor mounted, four-row boom sprayer delivering $800 \mathrm{~L} \mathrm{ha}^{-1}$ at $275 \mathrm{kPa}$ (Colorjet \# 80-28 nozzle, Delavan, Widnes, Cheshire, UK). On 25 June, 2 days after eggs were first observed, four plots per block were treated either with novaluron at $12.5,25$, or $50 \mathrm{~g} \mathrm{AI} \mathrm{ha}^{-1}$, or with imidacloprid at $48 \mathrm{~g} \mathrm{AI} \mathrm{ha}^{-1}$. Three other plots per block were treated with novaluron at 12.5 , 25 or $50 \mathrm{~g} \mathrm{AI} \mathrm{ha}^{-1}$ on 4 July, 2 days after second instars were first observed. Plots were treated with insecticide only once. One plot per block was not treated with insecticide. Weeds and pathogens were controlled by conventional methods (OMAF, 2004). The insect fauna on 10 randomly selected plants per plot was assessed ca. two times per week. Due to time constraints, plots treated 2 days after eggs were first observed were occasionally assessed on days different from those treated 2 days after second instars were first observed. Whole plants were inspected to determine the number of $L$. decemlineata adults, egg masses, small larvae (first and second instar), and large larvae (third and fourth instar). Populations of aphid (green peach aphid, Myzus persicae (Sulzer) and potato aphid, Macrosiphum euphorbiae (Thomas)), and potato leafhopper nymphs (Empoasca fabae (Harris)) were assessed by counting the number of individuals on three non-senescent trifoliate leaflets per plant. Potato flea beetle (Epitrix cucumeris (Harris)) damage was assessed by counting feeding punctures on two terminal leaflets from the lower third of the plant. In addition, beneficial insects including ladybird beetles, stinkbugs and spiders were counted on each plant.

Differences in numbers of $L$. decemlineata and other insects or damage per plant were determined for each collection date by ANOVA (SAS Institute, 1997). Multiple comparisons were conducted with the Tukey test $(\alpha=0.05)$. Data were square root transformed before analysis using the equation $X^{\prime}=\sqrt{X+0.5}$ (Zar, 1996), as a Shapiro-Wilk test found the data to be non-normal. Back-transformed data are presented in the results (SAS Institute, 1997). For brevity, only data for selected collection dates is presented. Complete data are available from the corresponding author upon request.

\subsection{Efficacy of novaluron-imidacloprid alternations - 2004}

Potato seed pieces (cv. Superior) were planted at the Simcoe Research Farm on 23 April in four-row, $13 \times 4 \mathrm{~m}$ plots in a randomized complete block design with four blocks per treatment. To prevent premature defoliation, $L$. decemlineata adults and egg masses were removed from plots up to 30 May. Adults were subsequently reintroduced at a rate of 175 adults per plot. Novaluron and imidacloprid were applied to potato foliage at 50 and $48 \mathrm{~g} \mathrm{AI} \mathrm{ha}^{-1}$, respectively as described in Section 2.2, using a tractor mounted, four-row boom sprayer delivering $800 \mathrm{~L} \mathrm{ha}^{-1}$ at $275 \mathrm{kPa}$. Treatments were: (1) untreated 
control; (2) imidacloprid followed by imidacloprid; (3) imidacloprid followed by novaluron; (4) novaluron followed by novaluron; and (5) novaluron followed by imidacloprid. Plots receiving an initial imidacloprid application were treated on 4 June, 2 days after adults were introduced. Those receiving an initial novaluron application were treated on 15 June at $20 \%$ second instar emergence, determined by monitoring development of randomly selected egg masses throughout the plots. The second insecticide treatment was applied when $L$. decemlineata densities exceeded 0.5 adults plant $^{-1}, 1.5$ small larvae (first or second instar) plant ${ }^{-1}$, or 1.5 large larvae (third or fourth instar) plant ${ }^{-1}$. Subsequent treatments for imidacloprid-imidacloprid and imidacloprid-novaluron plots were applied on 23 June, and on 7 July for novaluron-novaluron and novaluron-imidacloprid plots. All plots were treated with azinphosmethyl at $420 \mathrm{~g} \mathrm{AI} \mathrm{ha}^{-1}$, on 13 July to control immigrating second-generation adults that had emerged from control plots. In addition, dimethoate was applied to each plot on 23 June and 2 July, at a rate of $360 \mathrm{~g} \mathrm{AI} \mathrm{ha}^{-1}$, to control potato leafhopper. Weeds and pathogens were again controlled by conventional methods.

Twice per week, the number of $L$. decemlineata adults, egg masses, first, second, third, and fourth instars were recorded on eight randomly selected plants per plot. Counts of third and fourth instars have been combined in the results. Percent defoliation was assessed on the same eight plants using a defoliation index: $0=$ no defoliation; $1=$ up to $10 \%$ defoliation; $2=11-25 \%$ defoliation; $3=26-50 \% \quad$ defoliation; $4=51-75 \%$ defoliation; $5=76-100 \%$ defoliation. At the end of the trial, numbers of tubers and total tuber weight harvested from $5 \mathrm{~m}$ of each of the middle two rows per plot were determined. Only tubers $\geqslant 50 \mathrm{~mm}$ diameter were counted.

L. decemlineata and yield data were subjected to ANOVA and means were separated using the Tukey test $(\alpha=0.05)$. Data found to be non-normal were square root transformed before analysis, as described in Section 2.2 (Zar, 1996). Back-transformed data are presented in the results. Ranked defoliation data were analyzed with the Kruskal-Wallis test (SAS Institute, 1997). Results for selected collection dates are presented.

\section{Results}

\subsection{Optimal timing and rate of application-2003}

With the exception of 31 July, at which time secondgeneration adults emerged from control plots, numbers of adults in novaluron treated plots were not significantly different from those in control plots on any day $(P \leqslant 0.05)$. Although numbers of adults in imidacloprid treated plots were low, these were not significantly lower than numbers in control plots except on 31 July. Novaluron application did not affect the mean number of egg masses $(P \leqslant 0.05)$, at any application rate or timing. Mortality of $L$. decemlineata adults in imidacloprid-treated plots resulted in significantly fewer egg masses compared to the control during the first week of the experiment $(P \leqslant 0.05)$, but adults from control and novaluron plots thereafter migrated into imidacloprid treated plots, resulting in a subsequent increase in egg masses. Novaluron did not significantly reduce the number of small (first and second instar) larvae on any given day, regardless of rate or timing of application $(P \leqslant 0.05)$ (Table 1). Although there were few small larvae in imidacloprid treated plots early in the experiment, numbers eventually increased after adults migrated into plots. Plots treated with novaluron at rates of 25 and $50 \mathrm{~g} \mathrm{AI} \mathrm{ha}^{-1} 2$ days after second instars were first seen had significantly fewer $(P \leqslant 0.05)$ large larvae (third and fourth instar) than control plots throughout the whole experiment, except on the last data collection day when the number of large larvae dropped in all treatments (Table 2). At these rates, novaluron applied at the second instar stage provided protection from large $L$. decemlineata larvae as good as or better than that provided by imidacloprid. Throughout the experiment, numbers of large larvae were below 1 per plant in plots receiving $50 \mathrm{~g} \mathrm{AI} \mathrm{ha}^{-1}$ after second instars appeared. In contrast, novaluron treat ments applied 2 days after egg masses were first observed were not as effective (Table 2). Although numbers of large larvae on 10, 17, and 31 July were not always significantly different between novaluron $50 \mathrm{~g} \mathrm{AI} \mathrm{ha}^{-1}$ treatments, numerically there were up to 10 -fold as many larvae in plots treated after egg masses were first observed, at levels above the economic threshold. The $12.5 \mathrm{~g} \mathrm{AI} \mathrm{ha}^{-1}$ treatment applied at the egg stage provided no protection from large larvae $(P \leqslant 0.05)$, and the same rate applied after second instars were observed provided only some protection up to approximately 2 weeks after treatment (Table 2).

Beneficial insects, such as ladybird beetles (predominately Coleomegilla maculata DeGeer), stinkbugs, lacewing larvae, and spiders, were observed occasionally on plants throughout the trial. Ladybird beetle and stinkbug egg masses also were found. Numbers of natural enemies recorded, however, were not high enough to permit statistical analysis. However, partially eaten $L$. decemlineata egg masses were found in all plots, indicating some control due to natural enemies regardless of treatment.

Potato leafhopper densities were low during the first 4 weeks of the trial but increased thereafter. Significant differences in leafhopper densities were found amongst treatments on some days $(P \leqslant 0.05)$, but on no day was the lowest number found in a treatment significantly lower than that in the control. The number of flea beetle punctures per plant changed sporadically with no consistent treatment effect over time. Although significant differences amongst treatments were found some days $(P \leqslant 0.05)$, the lowest number of punctures found in a treatment was significantly lower than that in the control on 10 July only. Few aphids were found on plants throughout the trial and, therefore, statistical analysis could not be conducted. 
Table 1

Efficacy of novaluron (Rimon 10EC) and imidacloprid (Admire 240F) in 2003 for control of Colorado potato beetle (CPB), L. decemlineata, small (first and second instar) larvae on potato

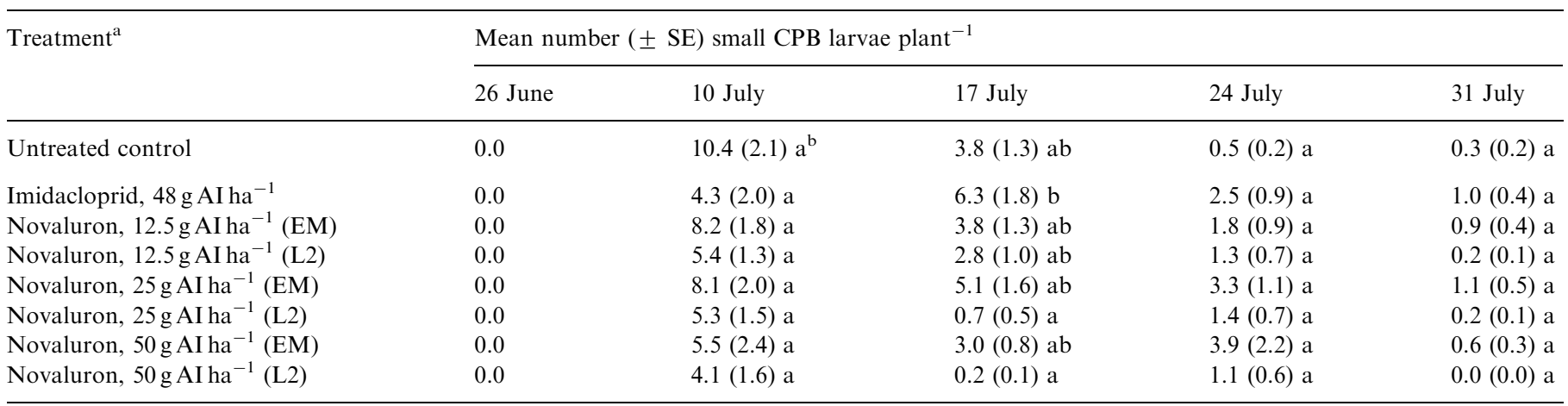

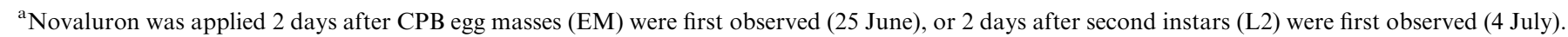
Imidacloprid was applied 2 days after EM were first observed.

${ }^{\mathrm{b}}$ Values within columns with different letters are significantly different from each other (Tukey test, $P<0.05$ ).

Table 2

Efficacy of novaluron (Rimon 10EC) and imidacloprid (Admire 240F) in 2003 for control of Colorado potato beetle (CPB), L. decemlineata, large (third and fourth instar) larvae on potato

\begin{tabular}{|c|c|c|c|c|c|}
\hline Treatment $^{\mathrm{a}}$ & \multicolumn{5}{|c|}{ Mean number $\left( \pm\right.$ SE) large CPB larvae plant ${ }^{-1}$} \\
\hline Untreated control & 0.0 & $9.2(1.8) \mathrm{a}^{\mathrm{b}}$ & $13.7(2.2) \mathrm{a}$ & $6.9(1.8) \mathrm{a}$ & $0.9(0.2) \mathrm{a}$ \\
\hline Imidacloprid, $48 \mathrm{~g} \mathrm{AI} \mathrm{ha}^{-1}$ & 0.0 & $2.0(0.6) \mathrm{bc}$ & $1.3(0.6) \mathrm{c}$ & $6.8(1.3) \mathrm{a}$ & $1.9(0.4) \mathrm{a}$ \\
\hline Novaluron, $12.5 \mathrm{~g} \mathrm{AI} \mathrm{ha}^{-1}$ (EM) & 0.0 & $6.6(1.5) \mathrm{ab}$ & $10.4(2.1) \mathrm{ab}$ & $8.0(1.6) \mathrm{a}$ & $0.9(0.3)$ a \\
\hline Novaluron, $12.5 \mathrm{~g} \mathrm{AI} \mathrm{ha}^{-1}$ (L2) & 0.0 & $1.2(0.4) \mathrm{c}$ & $3.7(0.8) \mathrm{c}$ & 4.8 (1.4) abc & $1.8(0.5) \mathrm{a}$ \\
\hline Novaluron, $50 \mathrm{~g} \mathrm{AI} \mathrm{ha}^{-1}$ (EM) & 0.0 & $3.2(0.9) \mathrm{bc}$ & $4.6(1.0) \mathrm{c}$ & $6.3(1.5) \mathrm{ab}$ & $2.5(0.7) \mathrm{a}$ \\
\hline Novaluron, $50 \mathrm{~g} \mathrm{AI} \mathrm{ha}^{-1}$ (L2) & 0.0 & $0.2(0.1) \mathrm{c}$ & $0.7(0.2) \mathrm{c}$ & $0.6(0.2) \mathrm{c}$ & $0.8(0.3) \mathrm{a}$ \\
\hline
\end{tabular}

\footnotetext{
${ }^{a}$ Novaluron was applied 2 days after CPB egg masses (EM) were first observed (25 June), or 2 days after second instars (L2) were first observed (4 July).
} Imidacloprid was applied 2 days after EM were first observed.

${ }^{\mathrm{b}}$ Values within columns with different letters are significantly different from each other (Tukey test, $P<0.05$ ).

\subsection{Efficacy of novaluron-imidacloprid alternations-2004}

No treatment regime consisting of an initial novaluron application caused significant reductions in either $L$. decemlineata adults or egg masses on any day $(P \leqslant 0.05)$. There also was no reduction in numbers of first instars (Fig. 1) following initial novaluron applications. Plots initially treated with imidacloprid had significantly fewer adults, egg masses, and first instars early in the experiment $(P \leqslant 0.05)$. However, adults from adjacent plots soon thereafter immigrated into the plots initially treated with imidacloprid, resulting in an increase in the number of first instars by 1 July (Fig. 1). Novaluron treatments resulted in significant reductions in the number of second instars, and third and fourth instars were almost completely suppressed throughout the trial (Fig. 1). Although the imidacloprid-imidacloprid treatment had significantly more third and fourth instars per plant at the end of the trial, they remained low in the imidacloprid-novaluron treatment (Fig. 1). As in 2003, natural enemy and aphid densities on plants were low and could not be analyzed statistically. While none of the treatment plots suffered more than $10 \%$ defoliation, defoliation of control plots was significantly greater such that by the end of the experiment some control plots were completely defoliated $\left(\chi^{2}=148.47 ; d f=4 ; P<0.0001\right)$. Plots that were treated with novaluron and/or imidacloprid also yielded significantly more tubers than untreated plots $(F=10.52 ; d f=4$; $P<0.0001$ ) (Table 3). Although there were no significant differences in potato yield amongst treated plots $(F=9.81$; $d f=4 ; P<0.0001$ ), yields were numerically highest in plots treated with the novaluron-imidacloprid. This treatment yielded $12 \%, 19 \%$, and $27 \%$ more potato than the novaluron-novaluron, imidacloprid-imidacloprid, and imidacloprid-novaluron treatments, respectively. On 10 June the plant pathogen Rhizoctonia solani Kühn was detected in some of the plants. By the end of the experiment, $R$. solani had infected most plants in all plots, resulting in leaf curl, wilting, root necrosis, leaf chlorosis, and likely reduced yields overall. 


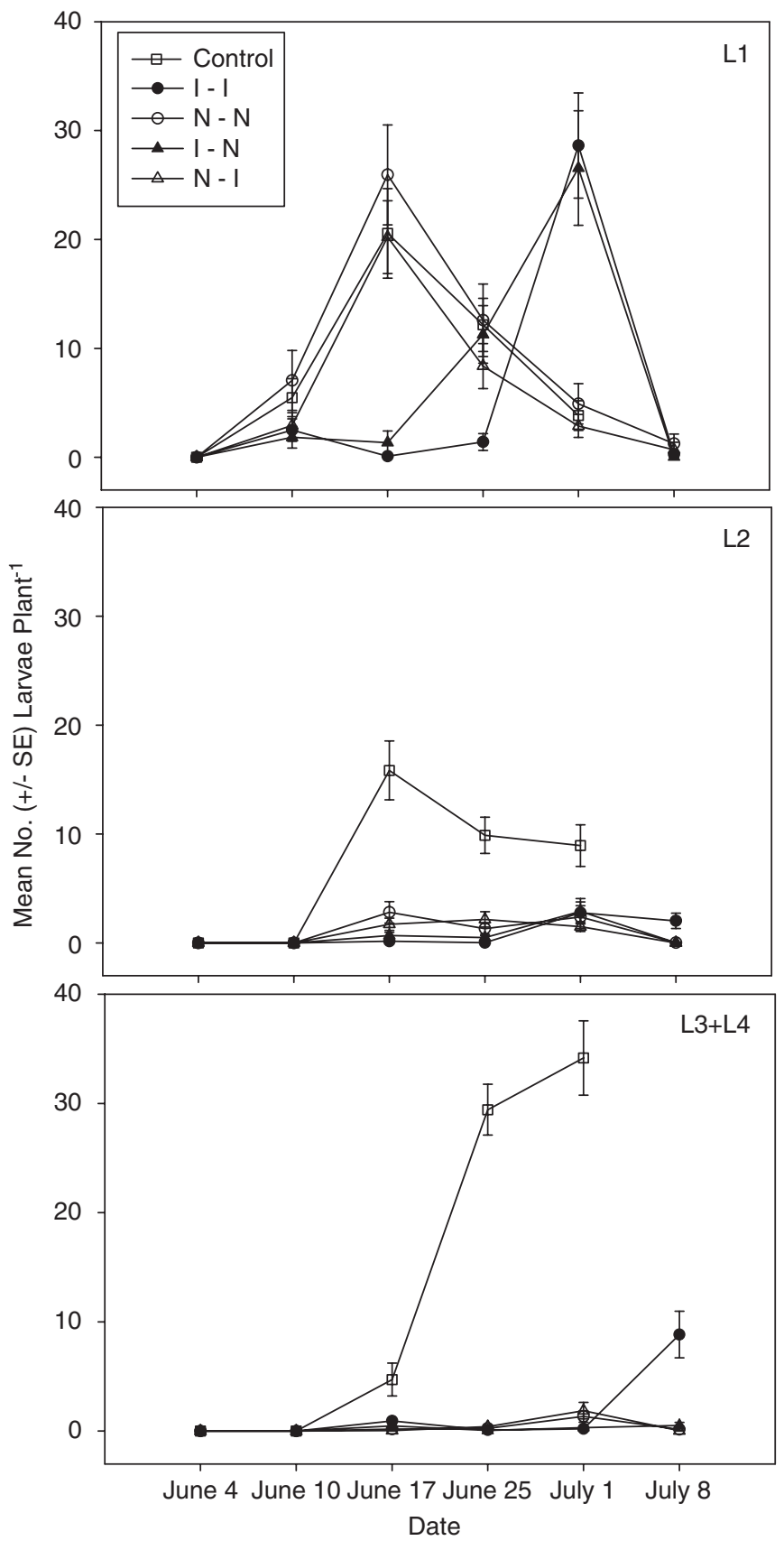

Fig. 1. Mean number $( \pm \mathrm{SE})$ Colorado potato beetle, $L$. decemlineata, first instar (L1), second instar (L2), and third and fourth instar (L3 + L4) larvae per potato plant after sequential treatments of novaluron $(\mathrm{N})$ (Rimon 10EC; $50 \mathrm{~g} \mathrm{AI} \mathrm{ha}^{-1}$ ) and/or imidacloprid (I) (Admire 240F; $48 \mathrm{~g} \mathrm{AI} \mathrm{ha}^{-1}$ ). Plants in control plots were completely defoliated by $8 \mathrm{July}$.

\section{Discussion}

Selective insecticides with modes of action different from those of broad-spectrum insecticides are highly desirable in $L$. decemlineata management programs. In addition to being useful in resistance management, the use of such compounds can conserve natural enemies (Hilbeck et al., 1998; Reed et al., 2001; Koss et al., 2005), which in turn potentially increases non-chemical mortality, possibly reducing reliance on insecticides. These experiments indicate that novaluron, a novel benzoylphenyl urea with demonstrated selectivity in favor of beneficial insects, can provide very good protection of potato from this pest. While as many as 14 large larvae per plant were found in control plots, single novaluron treatments of 25 or $50 \mathrm{~g} \mathrm{AI} \mathrm{ha}^{-1}$, applied 2 days after second instars were first observed, maintained the number of large larvae below three and one per plant, respectively, throughout the experiment. This level of control was as good as or better than that achieved with foliar imidacloprid treatments. Control of third and fourth instars is especially important since these stadia are usually responsible for over $90 \%$ of the defoliation caused by $L$. decemlineata (Hare, 1990). Malinowski and Pawinska (1992) found that a single treatment of novaluron suppressed univoltine populations below economic levels throughout the whole season in Poland. However, since at least two $L$. decemlineata generations occur in southern Ontario, it is unlikely that a single application would have provided adequate treatment throughout the season. Because Malinowski and Pawinska (1992) achieved close to $100 \%$ control with novaluron at $22.5 \mathrm{~g} \mathrm{AI} \mathrm{ha}^{-1}$, a $12.5 \mathrm{~g} \mathrm{AI} \mathrm{ha}^{-1}$ treatment was included in the present study. This rate of application, however, provided unsatisfactory control, suggesting that a minimum of $22.5 \mathrm{~g} \mathrm{AI} \mathrm{ha}^{-1}$ of novaluron is required to achieve good $L$. decemlineata control.

Application timing is usually more important for insect growth regulators, which target specific developmental processes, than for broad-spectrum insecticides. While good $L$. decemlineata control was achieved with novaluron in 2003 when second instars were targeted (applications 2 days after first observation or at $20 \%$ second instar emergence), treatments applied soon after eggs where first observed proved less effective. At the onset of oviposition, potato plants were early in their development. Therefore, the majority of foliage, developing after application, was not protected as the growing season progressed, resulting in higher population densities in this treatment. Although differences in control were not always statistically significant, fewer larvae were consistently found in treatments targeting second instars, as opposed to those targeting egg masses. Further, while novaluron treatments targeting egg masses did not suppress numbers of large larvae below Ontario's economic threshold of one larvae/plant (Anonymous, 2006), economic levels of control were usually maintained with treatments targeting second instars, especially at $50 \mathrm{~g} \mathrm{AI} \mathrm{ha}^{-1}$.

Malinowski and Pawinska (1992) suggested that success of novaluron against $L$. decemlineata would be greatest when applied early, at peak egg hatch. While their hypothesis may be correct, in practice precise determination of peak egg hatch will be difficult as adults oviposit continuously over several weeks in many growing regions. For this reason, distinctive population development milestones that can easily be identified by growers or pest 
Table 3

Potato yield from different management regimes for Colorado potato beetle (CPB), L. decemlineata, using foliar applications of novaluron (Rimon 10EC; $50 \mathrm{~g} \mathrm{AI} \mathrm{ha}^{-1}$ ) and/or imidacloprid (Admire 240F; $48 \mathrm{~g} \mathrm{AI} \mathrm{ha}^{-1}$ )

\begin{tabular}{llll}
\hline Treatment $^{\mathrm{a}}$ & No. tubers, $10 \mathrm{~m} \mathrm{row}^{-1}( \pm \mathrm{SE})$ & Weight $(\mathrm{kg}), 10 \mathrm{~m} \mathrm{row}^{-1}( \pm \mathrm{SE})$ & Estimated yield ha $^{-1}(\mathrm{~kg})$ \\
\hline Untreated control & $15.0( \pm 3.4) \mathrm{b}^{\mathrm{b}}$ & $1.3( \pm 0.3) \mathrm{b}$ & 1300 \\
Imidacloprid-imidacloprid & $48.9( \pm 3.2) \mathrm{a}$ & $5.4( \pm 0.3) \mathrm{a}$ & 5400 \\
Novaluron-novaluron & $51.4( \pm 4.5) \mathrm{a}$ & $5.9( \pm 0.9) \mathrm{a}$ & 5900 \\
Imidacloprid-novaluron & $44.6( \pm 5.0) \mathrm{a}$ & $4.9( \pm 0.5) \mathrm{a}$ & 4900 \\
Novaluron-imidacloprid & $54.0( \pm 7.3) \mathrm{a}$ & $6.7( \pm 1.1) \mathrm{a}$ & 6700 \\
\hline
\end{tabular}

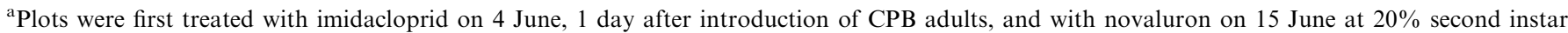
emergence. Subsequent applications occurred when CPB populations exceed the economic threshold in that treatment; 23 June for imidacloprid-imidacloprid and imidacloprid-novaluron plots, and on 7 July for novaluron-novaluron and novaluron-imidacloprid plots.

${ }^{\mathrm{b}}$ Values within columns followed by different letters are significantly different (Tukey test, $P<0.05$ ).

management consultants, were chosen in the present study. Based on previous research (Harcourt, 1971; Follet and Roderick, 1996; Cutler, unpublished), we estimated that $20 \%$ emergence would approximately correspond with peak egg hatch. Although novaluron applications at, for example, $30-50 \%$ second instar emergence may also have provided good control, we wanted to avoid development of problematic third and fourth instars and suspected that delaying applications beyond $20 \%$ emergence would allow establishment of some larger larvae.

As expected by its mode of action, novaluron applications had no effect on adult mortality. In contrast, applications of imidacloprid killed essentially all exposed adults, resulting in few egg masses and larvae during the 1st week of the experiments. However, adults thereafter emigrated from nearby control and novaluron plots to the imidaclopridtreated plots, resulting in subsequent increases in numbers of egg masses and larvae. While reinvasions from more distant sources might eventually occur, high rates of adult immigration would not generally be expected in commercial situations since entire fields would usually be treated with imidacloprid. We also found no reductions in number of first instars following novaluron treatments, although Malinowski and Pawinska (1992) and Cutler et al. (2005a) reported in field and laboratory experiments, respectively, that $L$. decemlineata females feeding on novaluron-treated foliage laid non-viable eggs.

The results from 2004 indicated that novaluron, alone or in alternation with imidacloprid, can greatly suppress numbers of second to fourth instar $L$. decemlineata larvae, thereby minimizing potato defoliation. Pest pressure was so high in 2004 that control plots were completely defoliated, and even denuded of stalks in many instances. The presence of $R$. solani throughout the field likely reduced overall yields, but yields from treated plots were much greater than those from control plots. Generally, there were no significant differences in pest densities, defoliation, or yield among the novaluron-novaluron, novaluron-imidacloprid, and imidacloprid-novaluron treatments. However, as frequent novaluron applications would increase the potential rate of evolution of populations of novaluronresistant beetles, growers keen on practicing good resis- tance management would do well to avoid two novaluron applications in a season. Further, for several reasons imidacloprid-novaluron applications may be preferable to novaluron-imidacloprid applications. First, since growers may have to wait several weeks after adult emergence from reproductive diapause to apply novaluron to larval stages, they may find it more reassuring to target emerged adults with imidacloprid, seeing immediate reductions in populations and damage. Second, since the interval of secondgeneration adult emergence is more protracted than that of the first, and the biological activity of foliar applied imidacloprid persists only 5-7 days, proper timing of later season imidacloprid applications would probably be more difficult. Foliar novaluron treatments, on the other hand, are much more persistent (Cutler et al., 2005b; current study) and therefore offer more flexibility in application timing later in the season. Third, later season novaluron applications avoid problems due to inadequate coverage of new foliage, which may be encountered early in the season when potato plants grow very rapidly. Indeed in 2003, novaluron applications at appearance of first egg masses occurred early in potato plant development, resulting in considerable untreated foliage as plants grew in following weeks. Fourth, effective alternation of insecticides during a season requires minimal overlap of the two pesticides within a generation to delay resistance development (Roush, 1989). Given the persistence of biological activity of novaluron on treated potato foliage is $4-5$ weeks (Cutler et al., 2005b; current study), it is likely that residues of an initial novaluron application would be present during a subsequent imidacloprid treatment. Even applied alone, an early novaluron application would impose strong selection for novaluron-resistant beetles throughout much of the first generation. A mid-late season novaluron treatment could be equally or even more effective following an imidacloprid in-furrow or seed treatment, the imidacloprid application methods of choice for many potato growers. However, while novaluron could eliminate immigrants or resistant survivors of imidacloprid in-furrow/seed-treatment applications, overlap of the two pesticides within a generation should still be avoided as much as possible (Roush, 1989). 
Novaluron provided no protection from potato leafhopper or potato flea beetle, emphasizing that in situations where management of these pests is warranted, additional insecticide applications or control tactics would be required. Although novaluron has shown good selectivity in favor of beneficial insects, densities of $L$. decemlineata predators were too low in the present study to permit comparisons amongst control and treatment plots. Also, it is likely that much larger plot sizes would be required to accurately assess effects on beneficials, since predators like ladybird beetles and stinkbugs may easily fly long distances.

Concerns over resistance to neonicotinoids (MotaSanchez et al., 2000, 2006; Olson et al., 2000; Tolman et al., 2005a) highlight the need to incorporate representatives of other chemical classes into $L$. decemlineata control programs. While other insecticides could serve this role, novaluron has several features that make it a good choice. Since its mode of action is completely different from that of imidacloprid, cross-resistance in imidacloprid-resistant beetles would be unlikely. Applications of novaluron would thus reduce selection pressure for imidaclopridresistant beetles. In addition, since larval stages, which are usually more sensitive to insecticides (Hilton et al., 1998; Zhao et al., 2000) and less capable of developing resistance than adults (Roush, 1989), would be targeted with this insect growth regulator, imidacloprid-resistant populations may be controlled with novaluron. Indeed, Cutler et al. (2005b) found that $L$. decemlineata larvae from adults previously exhibiting 91-fold resistance to imidacloprid were highly susceptible to novaluron. Furthermore, its selective properties should permit survival of natural enemies, providing an additional mortality factor and reducing reliance on insecticides. However, this hypothesis has not been vigorously tested; in laboratory experiments, Cutler et al. (2006) showed that the heteropteran Podisus maculiventris (Say), an important $L$. decemlineata predator, was susceptible to the compound. Finally, since novaluron is non-systemic, insecticide-free refugia will often exist in new plant growth (barring repeat application), permitting survival of susceptible genotypes and production of susceptible offspring in subsequent generations. Although this last point is certainly true if novaluron is used in alternation with imidacloprid foliar applications, imidacloprid from in-furrow or seed-treatments will be incorporated systemically into the plant, eliminating insecticidefree refugia for several weeks. Foliar imidacloprid residues from in-furrow or seed-treatments can be expected to gradually decline, however, after 6-8 weeks (Olson et al., 2004; Tolman et al., 2005b).

Application of insecticides has been the principal method of $L$. decemlineata control for well over a century, resulting in a management history peppered with repeated incidences of insecticide resistance (Casagrande, 1987; Bishop and Grafius, 1996). Although biological and cultural control can play important roles in $L$. decemlineata IPM, insecticides will remain a crucial management tool of growers for years to come. In this study, the insect growth regulator novaluron demonstrated very good potential to control key larval stages of this pest. It was successfully alternated with imidacloprid and would probably be equally effective if alternated with more recently introduced neonicotinoids such as acetamiprid and thiamethoxam. Used judiciously and combined with well-established IPM and resistance management practices, novaluron could be a valuable tool in future $L$. decemlineata management programs.

\section{Acknowledgments}

This work was funded by a Natural Sciences and Engineering Research Council Industrial Postgraduate Scholarship to GCC, sponsored by Crompton Co./Cie. Additional support was provided by Makhteshim-Agan of North America, the Ontario Ministry of Agriculture and Food-University of Guelph Plants Program, and Agriculture and Agri-Food Canada (Southern Crop Protection and Food Research Centre, London, Ont.). We acknowledge the technical assistance of Eric Roesler, Evelyn Dell, and Wally Andres.

\section{References}

Anonymous, 2006. Vegetable Production Recommendations 2006-2007. Queen's Printer for Ontario, Toronto, Ont.

Bishop, B.A., Grafius, E.J., 1996. Insecticide resistance in the Colorado potato beetle. In: Jolivet, P.H.A., Cox, M.L. (Eds.), Chrysomelidae Biology: The Classification, Phylogeny and Genetics. SPB Academic Publishing, Amsterdam, The Netherlands, pp. 355-377.

Cabrera, A.R., Cloyd, R.A., Zaborski, E.R., 2005. Lethal and sub-lethal effects of novaluron (Pedestal) on the soil-dwelling predatory mite, Stratiolaelaps scimitus (Womersley) (Acari: Mesostigmata: Laelapidae), under laboratory conditions. J. Entomol. Sci. 40, 47-53.

Casagrande, R.A., 1987. The Colorado potato beetle: 125 years of mismanagement. Bull. Entomol. Soc. Am. 33, 142-150.

Cutler, G.C., Scott-Dupree, C.D., Tolman, J.H., Harris, C.R., 2005a. Acute and sublethal toxicity of novaluron, a novel chitin synthesis inhibitor, to Leptinotarsa decemlineata (Say) (Coleoptera: Chrysomelidae). Pest Manage. Sci. 61, 1060-1068.

Cutler, G.C., Tolman, J.H., Scott-Dupree, C.D., Harris, C.R., 2005b. Resistance potential of Colorado potato beetle (Coleoptera: Chrysomelidae) to novaluron. J. Econ. Entomol. 98, 1685-1693.

Cutler, G.C., Scott-Dupree, C.D., Tolman, J.H., Harris, C.R., 2006. Toxicity of novaluron to the non-target predatory bug Podisus maculiventris (Heteroptera: Pentatomidae). Biol. Control 38, 196-204.

Follet, P.A., Roderick, G.K., 1996. Adaptation to insecticides in Colorado potato beetle: single- and meta-population models. In: Jolivet, P.H.A., Cox, M.L. (Eds.), Chrysomelidae Biology: Ecological Studies. SPB Academic Publishing, Amsterdam, the Netherlands, pp. 289-302.

Harcourt, D.G., 1971. Population dynamics of Leptinotarsa decemlineata (Say) in eastern Ontario. Can. Entomol. 103, 1049-1061.

Hare, J.D., 1990. Ecology and management of the Colorado potato beetle. Annu. Rev. Entomol. 35, 81-100.

Hilbeck, A., Eckel, C., Kennedy, G., 1998. Impacts of Bacillus thuringiensis insecticides on population dynamics and egg predation of the Colorado potato beetle in North Carolina potato plantings. Biocontrol 43, 65-75.

Hilton, S.A., Tolman, J.H., MacArthur, D.C., Harris, C.R., 1998. Toxicity of some insecticides to several life stages of Colorado potato beetle, Leptinotarsa decemlineata (Say). Can. Entomol. 130, 187-194. 
Ishaaya, I., Horowitz, A.R., 1998. Insecticides with novel modes of action: an overview. In: Ishaaya, I., Degheele, D. (Eds.), Insecticides with Novel Modes of Action. Springer, Berlin, Germany, pp. 1-24.

Ishaaya, I., Kontsedalov, S., Mazirov, D., Horowitz, A.R., 2001. Biorational agents: mechanisms and importance in IPM and IRM programs for controlling agricultural pests. Med. Fac. Landbouww. Univ. Gent. 66, 363-374.

Ishaaya, I., Horowitz, A.R., Tirry, L., Barazani, A., 2002. Novaluron (Rimon) a novel IGR: mechanism, selectivity and importance in IPM programs. Med. Fac. Landbouww. Univ. Gent. 67, 617-626.

Koss, A.M., Jensen, A.S., Schreiber, A., Pike, K.S., Snyder, W.E., 2005. Comparison of predator communities in Washington potato fields treated with broad-spectrum, selective, or organic insecticides. Environ. Entomol. 34, 87-95.

Linduska, J.J., Ross, M., Abbott, B., Steele, S., Eastman, R., 2001. Colorado potato beetle control on potatoes, 2000. Arthropod Management Tests 26. Report no. E51, 1p.

Linduska, J.J., Ross, M., Abbott, B., Steele, S., Ross, R., Eastman, R., 2002. Colorado potato beetle control on potatoes, 2001. Arthropod Management Tests 27. Report no. E69, 1p.

Malinowski, H., Pawinska, M., 1992. Comparative evaluation of some chitin synthesis inhibitors as insecticides against Colorado potato beetle Leptinotarsa decemlineata (Say). Pestic. Sci. 35, 349-353.

Mota-Sanchez, D., Whalon, M., Grafius, E., Hollingworth, R., 2000. Resistance of Colorado potato beetle to imidacloprid. Resist. Pest Manage. Newslett. 11, 31-34.

Mota-Sanchez, D., Hollingworth, R.M., Grafius, E.J., Moyer, D.D., 2006. Resistance and cross-resistance to neonicotinoid insecticides and spinosad in the Colorado potato beetle, Leptinotarsa decemlineata (Say) (Coleoptera: Chrysomelidae). Pest Manage. Sci. $62,30-37$.
Olson, E.R., Dively, G.P., Nelson, J.O., 2000. Baseline susceptibility to imidacloprid and cross resistance patterns in Colorado potato beetle (Coleoptera: Chrysomelidae) populations. J. Econ. Entomol. 93, 447-458.

Olson, E.R., Dively, G.P., Nelson, J.O., 2004. Bioassay determination of the distribution of imidacloprid in potato plants: Implications to resistance development. J. Econ. Entomol. 97, 614-620.

OMAF, 2004. Publication 363: Vegetable Production Recommendations 2004-2005. Queen's Printer for Ontario, Toronto, Ont.

Reed, G.L., Jensen, A.S., Riebe, J., Head, G., Duan, J.J., 2001. Transgenic $\mathrm{Bt}$ potato and conventional insecticides for Colorado potato beetle management: comparative efficacy and non-target impacts. Entomol. Exp. Appl. 100, 89-100.

Roush, R.T., 1989. Designing resistance management programs: how can you choose? Pestic. Sci 26, 423-441.

SAS Institute, 1997. JMP IN Version 3.2. SAS Institute, Cary, NC.

Sewell, G.H., Alyokhin, A., 2003. Control of Colorado potato beetle on potato, 2002. Arthropod Management Tests 28. Report no. E63, 1p.

Tolman, J.H., Hilton, S.A., Whistlecraft, J.W., McNeil, J.R., $2005 \mathrm{a}$. Susceptibility to insecticides in representative Canadian populations of Colorado potato beetle, Leptinotarsa decemlineata (Say). Resist. Pest Manage. Newslett. 15, 22-25.

Tolman, J.H., Mayo, K., Janssen, R., MacIntyre-Allen, J.K., Murray, R.L., Sawinski, T.A., 2005b. Microplot evaluation of treatments for control of insect pests of potato on mineral soil, 2004. 2004 Pest Management Research Reports, 2004 Growing Season. ECIPM, May 2005. Report no. 24, vol. 43, pp. 48-57.

Zar, J.H., 1996. Biostatistical Analysis. Prentice-Hall, Upper Saddle River, NJ.

Zhao, J., Bishop, B.A., Grafius, E.D., 2000. Inheritance and synergism of resistance to imidacloprid in the Colorado potato beetle (Coleoptera: Chrysomelidae). J. Econ. Entomol. 93, 1508-1514. 